\title{
Q\&A: Hard choices ahead for growing world
}

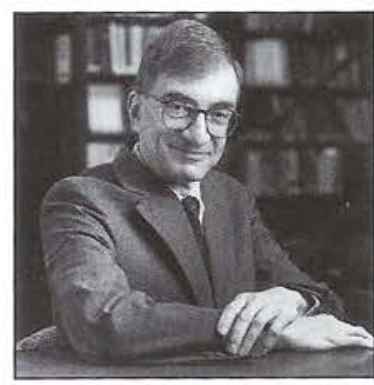

Joel E. Cohen

\section{Four-fifths of the world's population live in developing countries such as Bangladesh. Nearly half of the Earth's residents now crowd into cities.}

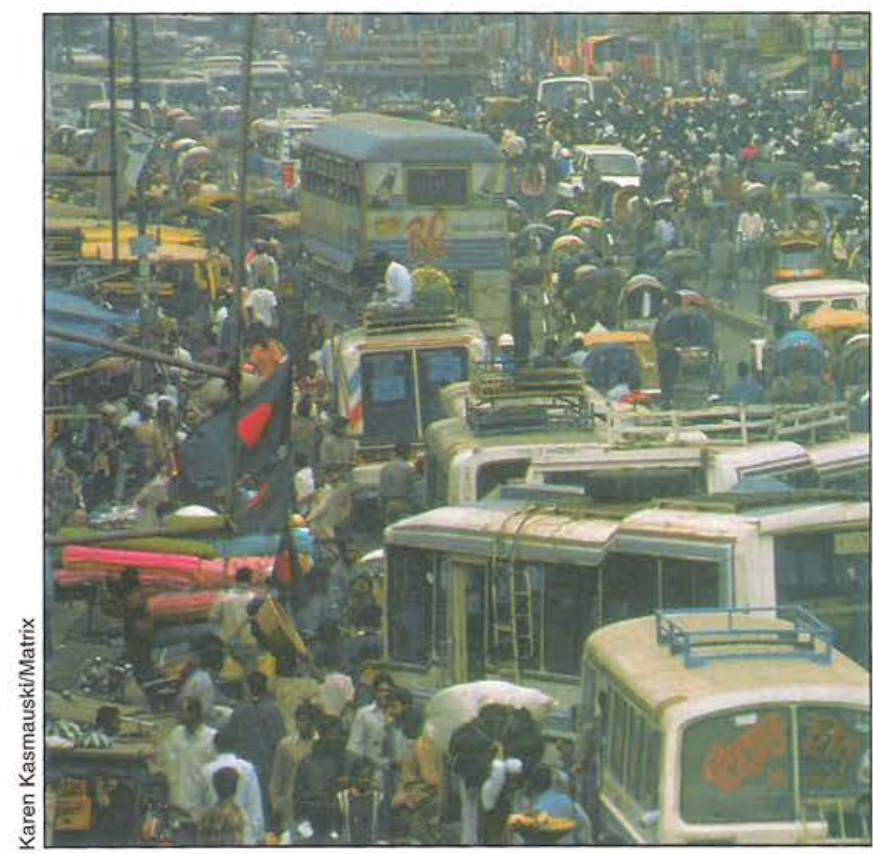

Joel E. Cohen is head of the Laboratory of Populations at Rockefeller University and Columbia University. Cohen earned doctorates in applied mathematics, population sciences and tropical public health from Harvard University. A world-renowned demographer and co-recipient of the Tyler Prize for Environmental Achievement in 1999, he is the author of How Many People Can the Earth Support? (1995).

While this special issue of California Agriculture focuses primarily on the impacts of population growth in California, Executive Editor Janet White asked Cohen to put the state's concerns into a global perspective.

The world's population changed dramatically in the 20th century. What can we expect in the century to come?

During the past century, the human population nearly quadrupled to 6 billion. Today more young people than ever before are entering childbearing age. Through sheer momentum, and barring catastrophe, their children will increase the world population by another 2 to 4 billion people by 2050 .

Perhaps the most important demographic event in the history of the human species, however, took place around 1965, when the world's annual growth rate began to decline from its peak of $2.1 \%$. After World War II, the industrialized countries learned how to export health without wealth. They provided cheap public health measures that dramatically lowered infant mortality in developing countries. As death rates dropped, growth rates in those countries shot up. It took from the end of World War II until 1965 for poorer countries to begin to control their fertility.

The 21st century is likely to see continued slowing, and perhaps even an end to population growth. Population is expected to reach 8 to 10 billion by mid-century.

The 20 th century will be the last in human history in which most people live in rural areas. The number of urbanites rose from 200 million to 2.9 billion between 1900 and 2000; today 47\% of people live in cities. The United Nations estimates that almost all population growth in the next half century will be in cities, while the rural population will remain near 3 billion people.

During the last century, the world's people shared very unequally in rising incomes. The average annual gross domestic product per person more than quadrupled to $\$ 5,200$, as the aggregate world economy grew 16-fold. Between 1960 and 1994 the disparity in per capita income between the richest and poorest fifths of the world's nations widened from 30 to 1 , to 78 to 1 . If the populations of developing countries continue to grow faster than those of industrialized countries, this gap could widen further.

\section{What problems are associated with projected population growth in developing countries and urban areas? \\ At present, about $80 \%$ of the world's popula-} tion lives in the poor, developing world. The rest live in the rich, industrialized world. The "rich" world consists of North America, Europe, Australia, Japan and New Zealand. The "poor" world is virtually everything else. While the poor already outnumber the rich, in the coming century there will be a further, massive shift in the relative sizes of the poor and rich sectors. At current rates, in one lifetime of 75 or 80 years the poor countries will increase by $400 \%$ while the rich countries will grow by about $8 \%$. The growth rates in the developing world will not be uniform, with the largest increases expected in certain countries of Africa, Latin America and Asia.

There are many problems that are associated with being poor and numerous. About a third of the earth's people are infected with the bacillus of tuberculosis; in Africa it's roughly half. Foodborne pathogens such as E. coli O157:H7 are more difficult to control, as crowded urban areas are less well-equipped with the basic means of sanitation. At present, about half the people in the world have no place to go to the toilet. 
What are the implications for world hunger?

Today the developing countries are importing massive amounts of food from the developed countries. Wheat and cereal yields have continued to rise steadily and the prices of major cereals have dropped dramatically. In world commodity markets the price of food is now cheaper than it has ever been.

A positive consequence is that the number of people in the world who are chronically hungry has dropped quite dramatically. In 1970, the FAO estimated that nearly a billion people were chronically hungry, more than a third of the population living in developing regions. In 1990, three-quarters of a billion people were hungry, about $20 \%$ of people living in developing regions. However, in Africa the number of chronically hungry people has grown from 100 million to 168 million.

How is it possible, if the price of food was cut in half, that more than three-quarters of a billion people are chronically hungry? The answer is that the very poor are economically invisible. They don't have cash and therefore cannot exert what economists call "effective demand" in world commodity markets. Prices are a poor indicator of scarcity, and are not a reliable measure of human well-being.

\section{How will energy use and the environment be affected?}

From 1860 to 1990 , there was a 5 -fold increase in the number of people on earth and a 19 -fold increase in per capita energy use, due primarily to the consumption or combustion of fossil fuel. Likewise, the aggregate impact of humans on biotic and geological processes grew enormously. In the 20th century, humaninduced emissions of carbon to the atmosphere grew from a half-billion tons to 7.3 billion tons per year, raising the carbon dioxide concentration in the atmosphere by about $20 \%$. World water withdrawals from all renewable freshwater sources grew 8 -fold in this century, to roughly 4,000 cubic kilometers per year. Humans now withdraw annually about a quarter to a half of all available renewable freshwater.

In the course of our demographic and economic expansion, humans have altered the habitats and populations of many other species, raising widespread concerns about extinction. For example, the area of cultivated land nearly doubled between 1900 and 1960. Since 1960, the area cultivated has not grown substantially. Rather, new lands have been converted to agriculture to replace lands abandoned or converted to nonagricultural uses, and the intensity

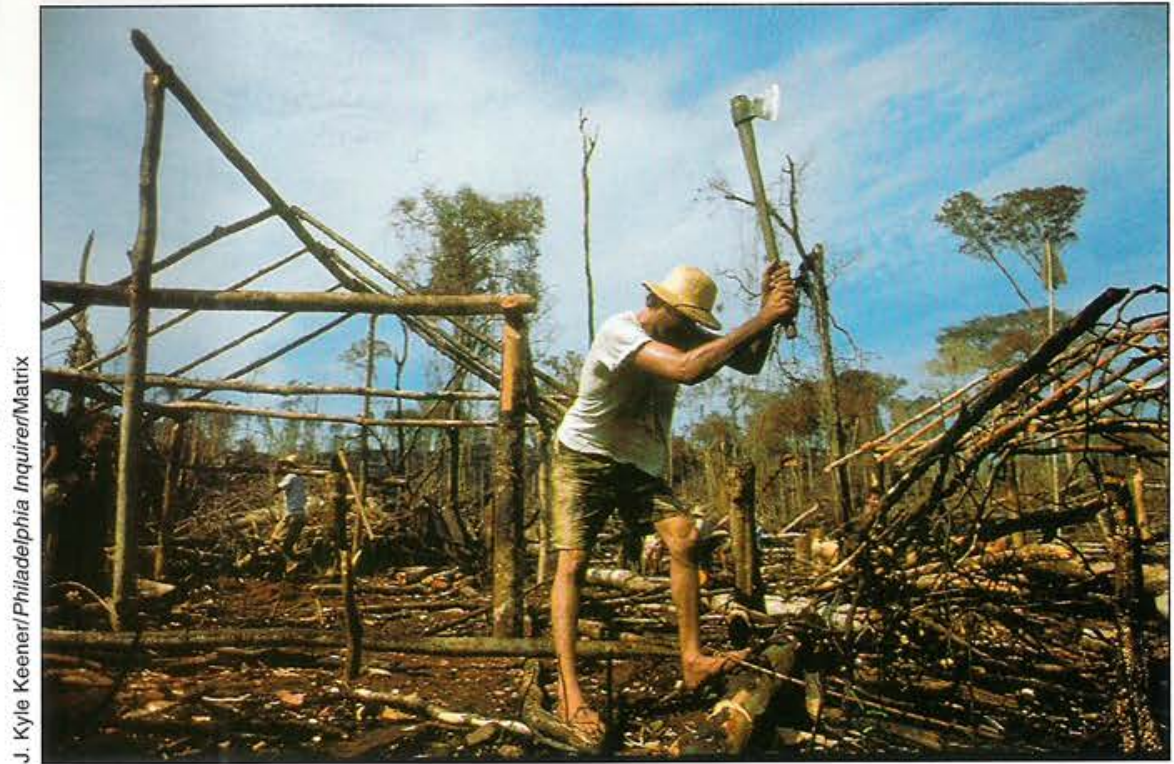

of cultivation and the yields per cultivated hectare have increased globally.

\section{How are cultural and economic changes expected to shape the 21 st century?}

It's not just population versus the environment; their interaction with culture, government and the economy must also be considered. In Brazil, for example, when interest rates are low, capital is cheap and roads can be built into new blocks of forest making it easier for peasants to deforest large areas of land. When interest rates are high, fewer roads are built and large blocks of land are nibbled at from the edges. Another factor is government regulation of the forest, and what economic activities are allowed or encouraged.

The situation of women in the economy has also changed radically in the last generation. In 1970 there were 37 working women for every 100 working men in the world, with wide variations from country to country. Twenty years later, that number has nearly doubled to 62 working women for every 100 working men. The labor force is not dependent solely on population growth but on what are culturally acceptable activities for women.

Likewise, primary education has become the norm in Western Europe, North America, and the most industrialized nations of Asia and the Pacific. However, only three-quarters of the children eligible to attend primary schools in developing countries do so today, and the 130 million children who are out of school are disproportionately girls.
Economic factors such as interest rates can influence the progress of deforestation. Here, squatters in Brazil's Amazon rain forest clear tracts of endangered habitat. 